\title{
Achieving superplasticity through severe plastic deformation
}

\author{
M. Kawasaki ${ }^{1,2}$, R. B. Figueiredo ${ }^{3}$, T. G. Langdon ${ }^{2,4 \dagger}$ \\ †langdon@usc.edu
${ }^{1}$ Division of Materials Science and Engineering, Hanyang University, Seoul 133-791, South Korea
${ }^{2}$ Departments of Aerospace \& Mechanical Engineering and Materials Science, University of Southern California, Los Angeles, CA 90089-1453, U. S. A 31270-901, MG, Brazil
${ }^{4}$ Materials Research Group, Faculty of Engineering and the Environment, University of Southampton, Southampton SO171BJ, U. K \\ ${ }^{3}$ Department of Materials Engineering and Civil Construction, Universidade Federal de Minas Gerais, Belo Horizonte
}

\begin{abstract}
The processing of metals through the application of severe plastic deformation (SPD) provides an opportunity for refining the grains to the submicrometer or even the nanometer range in bulk materials. In principle, these ultrafine-grained materials should be ideal for achieving excellent superplastic properties but in practice this requires also that the microstructure has reasonable stability when testing in tension at elevated temperatures. Attaining superplastic elongations is an important prerequisite for using metals in commercial superplastic forming applications. Accordingly, this review briefly summarizes the principles of grain refinement in f.c.c. and h.c.p. metals where the mechanisms of grain refinement are different in these different crystal structures. The exceptional grain refinement produced by SPD techniques leads to excellent superplastic properties in many different materials. Especially, controlling the processing parameters of SPD techniques and using twophase alloys are useful strategies for achieving excellent superplastic properties in metallic materials. This report presents numbers of examples of superplastic flow in several different metals and alloys processed by two representative SPD processing techniques of equal-channel angular pressing (ECAP) and high-pressure torsion (HPT). Finally, it is now possible to evaluate the flow process in superplasticity and this provides an opportunity to present the experimental data in terms of a deformation mechanism map.
\end{abstract}

Keywords: deformation mechanism map, flow mechanism, grain refinement, severe plastic deformation, superplasticity

\section{Достижение сверхпластичности путем интенсивной пластической деформации}

Обработка металлов путем приложения интенсивной пластической деформации (ИПД) дает возможность измельчения зерен в объемных материалах вплоть до субмикрометрического или даже нанометрического масштаба. В принципе, эти ультрамелкозернистые материалы должны быть идеальными для достижения исключительно высоких сверхпластических свойств, однако на практике это требует также, чтобы микроструктура имела достаточную стабильность при испытаниях растяжением при повышенных температурах. Достижение сверхпластических удлинений является важной предпосылкой использования металлов в промышленных процессах сверхпластического формообразования. Соответственно, настоящий обзор кратко обобщает принципы измельчения зерен в г.ц.к. и г.п.у. металлах, в которых механизмы измельчения различаются из-за отличия кристаллических структур. Экстраординарное измельчение зерен, вызываемое методами ИПД, приводит к исключительно высоким сверхпластическим свойствам во множестве различных материалов. В особенности, контроль параметров обработки при ИПД и использование двухфазных сплавов представляют собой успешные стратегии для достижения наиболее высоких сверхпластических свойств в металлических материалах. В обзоре представлено множество примеров сверхпластического течения в нескольких различных металлах и сплавах, подвергнутых обработке двумя представительными методами ИПД - равноканальным угловым прессованием (РКУП) и кручением под высоким давлением (КВД). И, наконец, в настоящее время можно количественно характеризовать процесс течения при сверхпластичности, и это дает возможность представить экспериментальные данные в виде карты механизмов деформации.

Ключевые слова: карта механизмов деформации, механизм течения, интенсивная пластическая деформация, сверхпластичность 


\section{Introduction}

Grain refinement is a standard procedure used in industry in order to obtain a significant strengthening of the material. This refinement is usually achieved through thermomechanical processing but in practice the conventional processing is not capable of reducing the grain size below the level of a few micrometers. Over the last two decades, it has become clear that more substantial grain refinement may be achieved by processing metals through the application of severe plastic deformation (SPD) $[1,2]$. At the present time the two major SPD processing methods are equal-channel angular pressing [3] and high-pressure torsion (HPT) [4] and both of these techniques provide a capability for reducing the grain size to within the submicrometer or even the nanometer range.

In principle, it appears that the ultrafine-grained (UFG) materials produced by SPD processing should exhibit excellent superplastic properties because superplasticity requires a very small grain size which is typically below $\sim 10$ $\mu \mathrm{m}$ [5]. In practice, however, superplastic flow also requires a high testing temperature, within the range where diffusion is important, so that the testing temperature must be at or above $\sim 0.5 T_{m}$ where $T_{m}$ is the absolute melting temperature of the material. Provided the UFG microstructures produced by SPD processing are retained at high temperatures then, as shown in recent reviews, it is possible to achieve excellent superplastic properties when processing by either ECAP [6] or HPT [7].

The following sections describe the processes of grain refinement in f.c.c. and h.c.p. metals when using SPD and then give examples of superplasticity for several different materials. It includes a demonstration of the potential for depicting the flow processes in superplastic materials using a deformation mechanism map.

\section{Grain refinement in UFG metals}

Figure 1 is a schematic illustration of the characteristics of grain refinement in an f.c.c. metal, such as aluminum, when processed by ECAP using a die with an angle of $90^{\circ}$ between the channels [8]: the three rows correspond to 1,2 and 4 passes (p) and the three columns are for processing routes $\mathrm{A}, \mathrm{B}_{\mathrm{C}}$ and $\mathrm{C}$, where $\mathrm{A}$ denotes repetitively pressing through an ECAP die without sample rotation, $\mathrm{B}_{C}$ denotes a rotation of $90^{\circ}$ in the same sense between each pass and $\mathrm{C}$ denotes rotation by $180^{\circ}$ between passes [9]. The illustrations in Fig. 1 represent the $\mathrm{Y}$ plane in ECAP processing where there are three orthogonal planes in which $\mathrm{X}$ is the transverse plane perpendicular to the flow direction, $\mathrm{Y}$ is the flow plane parallel to the side face at the point of exit from the ECAP die and $\mathrm{Z}$ is the longitudinal plane parallel to the top surface at the point of exit from the die. In Fig. 1 each pass is represented by a different color and red, mauve, green and blue correspond to the slip planes introduced in the first, second, third and fourth pass, respectively.

Thus, in the first pass the shearing is confined exclusively to planes lying at $45^{\circ}$ to the $\mathrm{X}$ axis and this produces a band of subgrain boundaries with low-angles of misorientation and with a subgrain width equal to $d$. In the second, third and fourth passes, additional sets of subgrain bands are formed and these are delineated in Fig. 1 with the colored lines marked 2p, 3p and $4 p$. The spectrum of slip for each plane and each processing route may be readily represented by $\eta$ which defines the total angular range containing all slip systems. Thus, it follows from Fig. 1 that route $\mathrm{BC}$ is the most effective processing route because after 4 passes the total angular range is given by $\eta=63^{\circ}$. Since route BC produces numerous intersecting slip systems, it leads to a high density of dislocations and these dislocations are then able to re-arrange and annihilate consistent with the LEDS (low energy dislocation structure) theory [10] giving the formation of an array of reasonably equiaxed grains. It follows, therefore, that the development of slip on multiple slip systems in f.c.c. metals is consistent with the easy formation of a UFG structure.

The process of grain refinement is different for h.c.p. metals because the numbers of active slip systems are limited. For example, the slip systems with the lowest critical resolved shear stress in magnesium are along the basal plane but these systems alone cannot account for plastic deformation in multiple directions. As a consequence, magnesium exhibits limited ductility at room temperature. Other slip systems become active at higher temperatures so that forming operations can be carried out.

Early experiments [11] showed that a magnesium alloy exhibits dynamic recrystallization at temperatures above 423 $\mathrm{K}$ and the new grains are formed along the original grain boundaries leading to a necklace-like pattern of fine grains. This pattern formation of new grains was also observed in a ZK60 alloy [12]. As a result of this mechanism of dynamic recrystallization, the grain structure attains a multi-modal
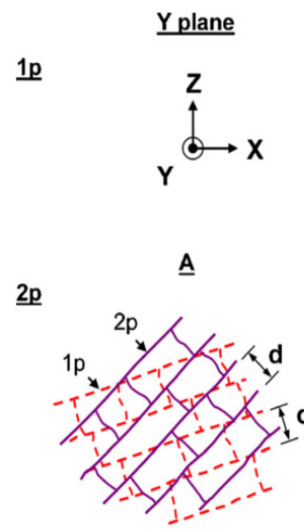

$\underline{\eta}=27^{\circ}$

$\underline{4 p}$

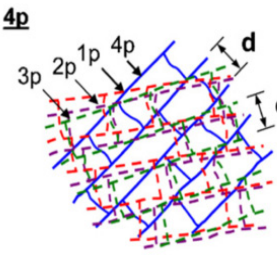

$\underline{\eta}=37^{\circ}$
$\underline{A}$

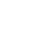
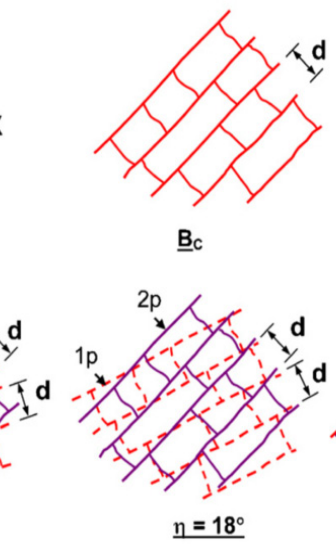

$\underline{B} c$

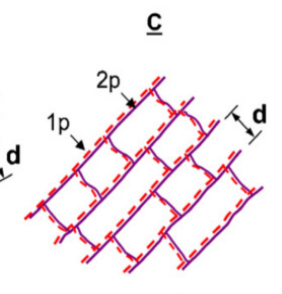

$\underline{n}=0^{\circ}$
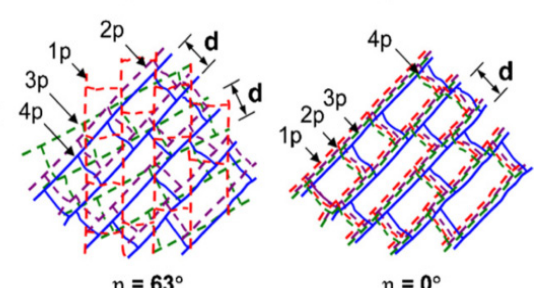

$\underline{\eta}=0^{\circ}$

Fig. 1. A model for grain refinement in ECAP where subgrain bands are formed, with a width of $d$, with their longer sides lying parallel to the primary slip plane: results are illustrated on the Y plane for 1, 2 and 4 passes using routes $\mathrm{A}, \mathrm{B}_{\mathrm{C}}$ and $\mathrm{C}$ with the colors red, mauve, green and blue corresponding to the first, second, third and fourth pass through the die, respectively [8]. 
size distribution with some new fine grains and some coarse grains that remain in the interiors of the old grains. Also, the new fine grains can generate a softer shear zone leading to macroscopically inhomogeneous deformation [11].

Thus, the grain refinement mechanism in magnesium alloys differs from f.c.c. metals because it must take into account the necklace-like dynamic recrystallization and the concentration of deformation across the new fine grains. The grain structure evolution depends on the initial grain size, the size of the new grains and the amount of strain imposed. A model was proposed for grain refinement in magnesium processed by ECAP [13] and this was later improved as shown in Fig. 2 [14]. The model is based on microstructural evolution reported in the literature. Thus, the left column shows different initial grain structures from coarse (top) to fine (bottom), the middle column shows the grain structure after low numbers of ECAP passes and the right column shows the structure after multiple passes. The new grains are represented in gray while the original grains are depicted with a white background. It is observed in the top row that an initial coarse-grained structure will evolve into a multi-modal grain size distribution if the new grains are small. The second row from the top shows that an initial coarse-grained structure can evolve into a homogeneous

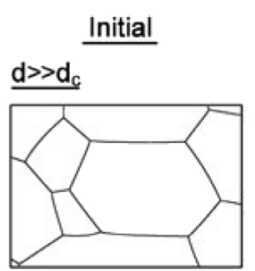

(a)

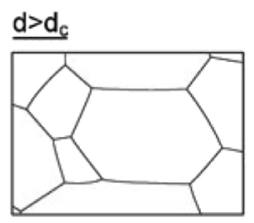

(d)

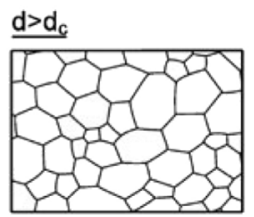

(g)

$\underline{\mathrm{d}<\mathrm{d}_{\mathrm{c}}}$

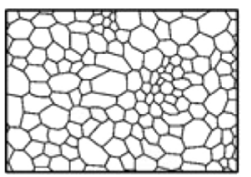

(j)
After ECAP

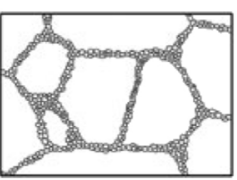

(b)

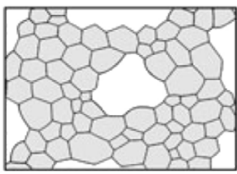

(e)

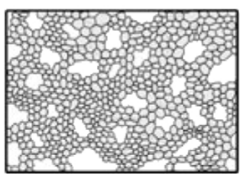

(h)

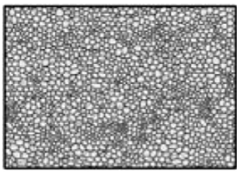

(k)

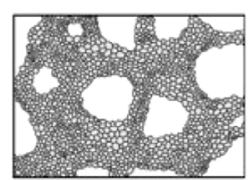

(c)

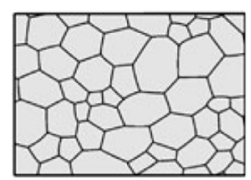

(f)

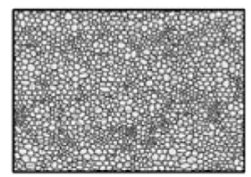

(i)
Fig. 2. A model for the grain refinement of magnesium alloys processed by ECAP: the left column shows the initial condition, the second column shows the structure after one pass and the third column shows the structure after multiple passes; the upper two rows represent the same initial structure with different processing parameters and the third and fourth rows display different initial structures [14]. distribution of grains if the size of the new grains is not significantly smaller than the initial grain size. The bottom rows show that an homogeneous distribution of fine grains can be achieved if the starting structure is not coarse. The latter processing route is readily achieved by the introduction of a preliminary step of thermo-mechanical processing in magnesium such as by using extrusion. The use of extrusion followed by ECAP is now well established and the process was named EX-ECAP $[15,16]$. Although the mechanism of grain refinement in magnesium differs from f.c.c. metals, there are many processing routes capable of producing homogeneous ultrafine-grained structures and introducing excellent superplastic properties in the materials.

\section{Superplasticity in SPD materials}

The exceptional grain refinement achieved through SPD processing suggests that these materials may be ideal for attaining excellent superplastic properties. In practice, however, the occurrence of superplastic flow requires a high level of microstructural stability when the SPD materials are tested at elevated temperatures.

This requirement was recognized in early studies of SPD materials and it led to extensive investigations of the thermal stability of UFG structures. For example, it was shown in early experiments that pure $\mathrm{Al}$ and $\mathrm{Al}$ alloys with a $\mathrm{Mg}$ additive are not thermally stable at high temperatures but a reasonable level of microstructural stability may be achieved by adding Sc or $\mathrm{Zr}$ to retain these very small grain sizes $[17,18]$.

In conventional superplasticity, it has been shown both experimentally [19] and theoretically [20] that the strain rate varies inversely with the grain size raised to a power approximately equal to two. Therefore, since the superplastic range of strain rates increases with decreasing grain size, this led to the suggestion that SPD materials should exhibit superplasticity at exceptionally rapid strain rates [21]. The first example of this effect is shown in Fig. 3 where a commercial aluminum 01420 alloy with a composition of Al-5.5\% Mg$2.2 \% \mathrm{Li}-0.12 \% \mathrm{Zr}$ was processed by ECAP to produce a grain size of $\sim 1.2 \mu \mathrm{m}$ and then pulled in tension at $623 \mathrm{~K}$ at initial strain rates of $1.0 \times 10^{-2}$ and $1.0 \times 10^{-1} \mathrm{~s}^{-1}$ [22]. At the lower strain rate the specimen pulled out to $\sim 1180 \%$ and the test was then terminated without failure and at the faster strain rate the specimen failed at an elongation of $~ 910 \%$. Both of these results are consistent with the requirements for high strain rate superplasticity where superplastic elongations

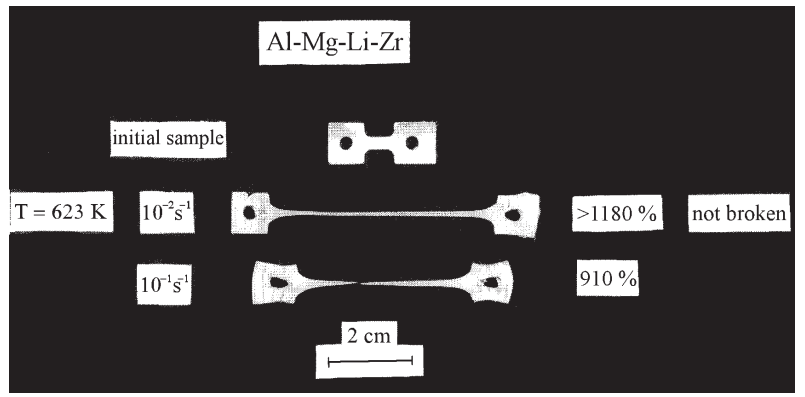

Fig. 3. The first example of high strain rate superplasticity in an alloy subjected to SPD processing [22]. 
occur at strain rates at and above $10^{-2} \mathrm{~s}^{-1}$ [23]. Similar high elongations at very high strain rates were also obtained using a commercial Al-2004 alloy with a composition of Al-6\% Cu$0.4 \% \operatorname{Zr}[22]$.

As noted in section 2, a combination of extrusion and ECAP, termed EX-ECAP, is now widely used for the SPD processing of magnesium alloys. This leads to excellent superplastic properties and an example is shown in Fig. 4 for a two-phase Mg-8\% Li alloy [24]. The upper results marked Cast + Extrude + ECAP were obtained by processing an extruded alloy by ECAP at room temperature and then testing in tension over a range of strain rates at $473 \mathrm{~K}$ : the ECAP was conducted using a die with an angle between the channels of $135^{\circ}$ and an arc of curvature of $\sim 20^{\circ}$ so that the strain imposed in each separate pass was $\sim 0.5$ [25] and the extrusion was conducted at $373 \mathrm{~K}$ using an extrusion speed of $1 \mathrm{~mm} \mathrm{~s}^{-1}$. Also shown in Fig. 4 are results obtained for the same alloy in the Cast + Extrude condition without ECAP and in the Cast condition without extrusion or SPD processing. It is readily apparent that the cast alloy with a grain size of $\sim 60-70 \mu \mathrm{m}$ is not superplastic, the cast alloy processed by extrusion to produce a grain size of $\sim 3-4 \mu \mathrm{m}$ shows limited superplasticity at the slowest strain rate whereas processing by the EX-ECAP process produces excellent superplasticity with ductilities up to $1800 \%$.

The introduction of ultrafine grained structures in magnesium alloys provides the opportunity for developing superplastic properties. However, as shown in section 2, the mechanism of grain refinement of magnesium alloys differs from f.c.c. metals since it depends on the initial grain structure and the number of passes of ECAP. The superplastic behavior of magnesium alloys processed by ECAP also varies depending on processing parameters. Early reports of superplasticity in magnesium alloys were limited to strainrates of $3 \times 10^{-3} \mathrm{~s}^{-1}$ or lower $[15,16,26-31]$. The limitation of superplasticity to slow strain rates was attributed to poor thermal stability of the magnesium alloys that prevented testing at high temperatures where diffusion is faster. For example, it was shown that the optimum strain rate for su-

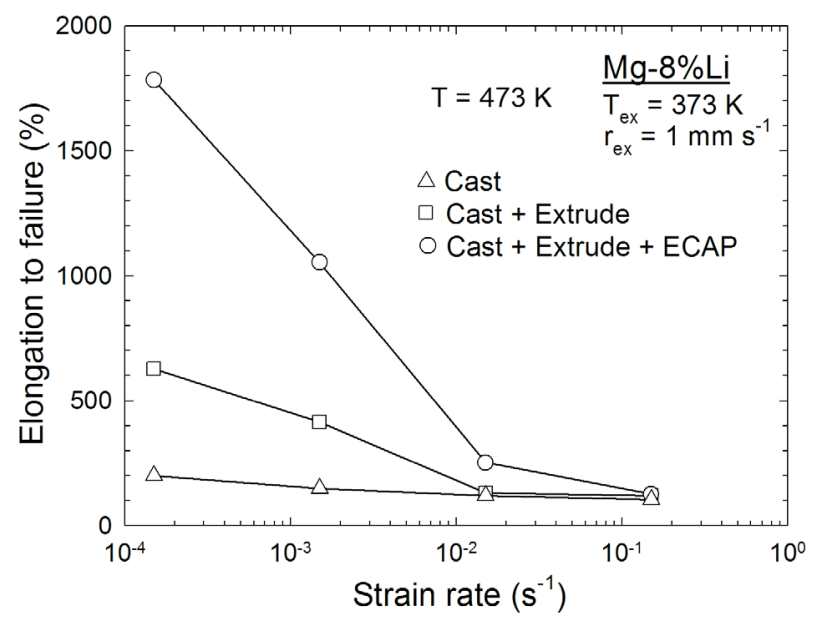

Fig. 4. Variation of the elongation to failure with the initial strain rate at a temperature of $473 \mathrm{~K}$ for samples in the Cast, Cast + Extrude and Cast + Extrude + ECAP conditions: the extrusion was conducted at $373 \mathrm{~K}$ using an extrusion speed of $1 \mathrm{~mm} \mathrm{~s}^{-1}$ [24]. perplasticity increases from $3 \times 10^{-5} \mathrm{~s}^{-1}$ at $450 \mathrm{~K}$ to $3 \times 10^{-4} \mathrm{~s}^{-1}$ at $473 \mathrm{~K}$ in a ZK60 alloy processed by ECAP but a further increase in testing temperature leads to grain growth and a consequent loss of superplasticity [32]. Later it was shown that high strain rate superplasticity can be achieved in this alloy by controlling the processing parameters [33]. It was shown that reducing the number of ECAP passes or increasing the ECAP processing temperature from 473 to $513 \mathrm{~K}$ increases the thermal stability of the structure and high strain rate superplasticity was reported [33].

Also, controlling the number of ECAP passes affects significantly the maximum elongation to failure observed in magnesium alloys. It has been shown that increasing the number of passes increases the elongation observed in the AZ31 alloy [34]. On the other hand, a reduced number of passes of ECAP leads to larger elongations in the ZK60 alloy [34-36]. The effect of the number of passes of ECAP on the final elongation of the ZK60 alloy is shown in Fig. 5a [35]. The material was processed from the extruded condition and tested at $473 \mathrm{~K}$ with an initial strain rate of $1.0 \times 10^{-4} \mathrm{~s}^{-1}$. It is observed that the elongation to failure increases with ECAP processing up to 2 passes and decreases with further processing. The reduction in elongation with large numbers of passes of ECAP is attributed to poorer thermal stability of the grain structure that leads to faster dynamic grain growth at large numbers of passes [36]. The dynamic grain growth is responsible for the pronounced strain hardening observed in this material during tensile testing under superplastic conditions. Figure $5 \mathrm{~b}$ shows the stress vs. strain curve observed in the material processed by 2 passes of ECAP and the material processed by 6 passes together with the strain hardening rate normalized by the strain rate sensitivity for both conditions. The theory for tensile stability predicts that necking begins at the intersection of these curves. Therefore, the strain hardening of both curves promotes high uniform elongations in both conditions but the higher flow stress observed in the material processed by 6 passes leads to an intersection of the curves at a lower strain which triggers premature necking. Also, the deformation after plastic instability, which is controlled by the strain rate sensitivity, is larger in the material with lower numbers of passes due to the finer grain structure.

It is important to note that tensile testing of the $\mathrm{Zn}-\mathrm{Al}$ alloys processed by ECAP and HPT demonstrates that, as in conventional superplastic materials without processing through SPD, superplasticity occurs over a limited range of strain rates, and these ductilities decrease at both faster and slower strain rates. In practice, the plastic deformation visible in Fig. 6 corresponds to the three regions of flow in superplasticity where region II is true superplasticity with high elongations at intermediate strain rates, region III represents a transition to conventional dislocation creep at faster strain rates, and region I represents a regime of flow which is impurity dependent at the slowest strain rates [44].

For a better understanding of the flow process of the $\mathrm{Zn}$-Al alloys after SPD processing, a deformation mechanism map was constructed for the alloy where the result is shown in Fig. 7 in the form of a map plotting the normalized grain size against the normalized stress for a constant temperature of $473 \mathrm{~K}$. Specifically, regions I, II, and III denote the three regions of flow associated with conventional superplastic 


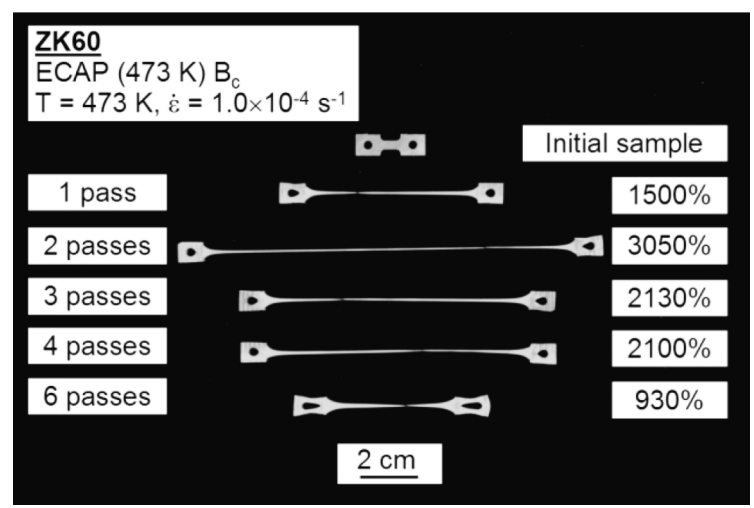

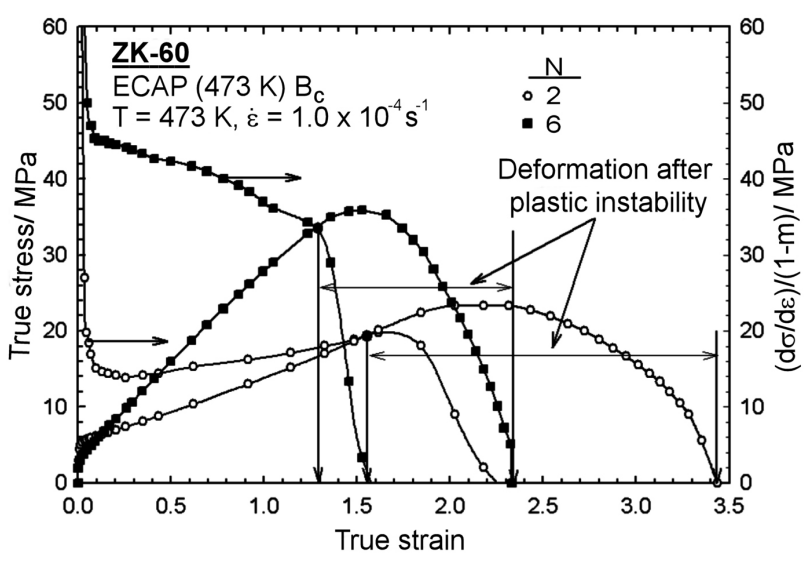

$\mathrm{b}$

Fig. 5. (a) Appearance of specimens tested to failure at $473 \mathrm{~K}$ with an initial strain rate of $1.0 \times 10^{-4} \mathrm{~s}^{-1}$ after processing by ECAP for different numbers of passes: the upper specimen is untested and (b) true stress and the rate of strain hardening normalized by $(1-m)$ as a function of the true strain for two samples processed by ECAP through 2 and 6 passes: the intersections of the two curves mark the onset of plastic instability [35].

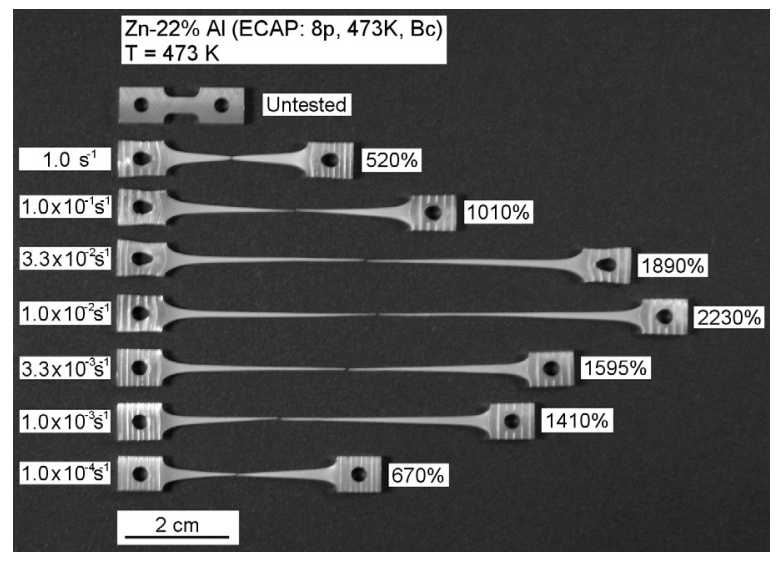

a

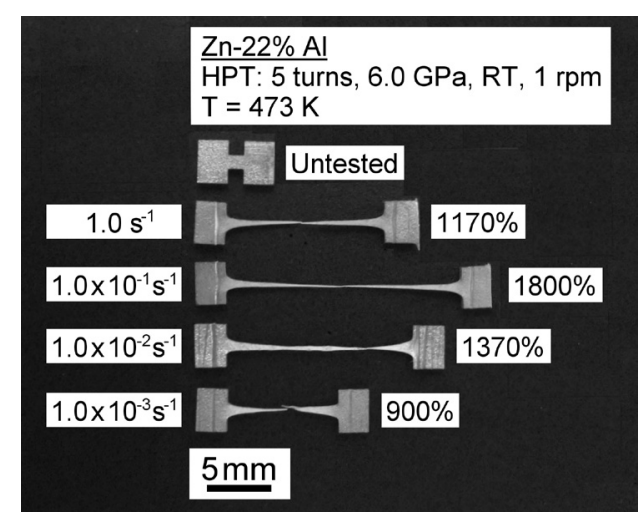

$\mathrm{b}$

Fig. 6. The appearance of the specimens processed by (a) ECAP for 8 passes at $473 \mathrm{~K}$ and pulled to failure at seven different strain rates at 473 $\mathrm{K}$ [41] and (b) HPT for 5 turns and pulled to failure at different strain rates at $473 \mathrm{~K}$ [43].

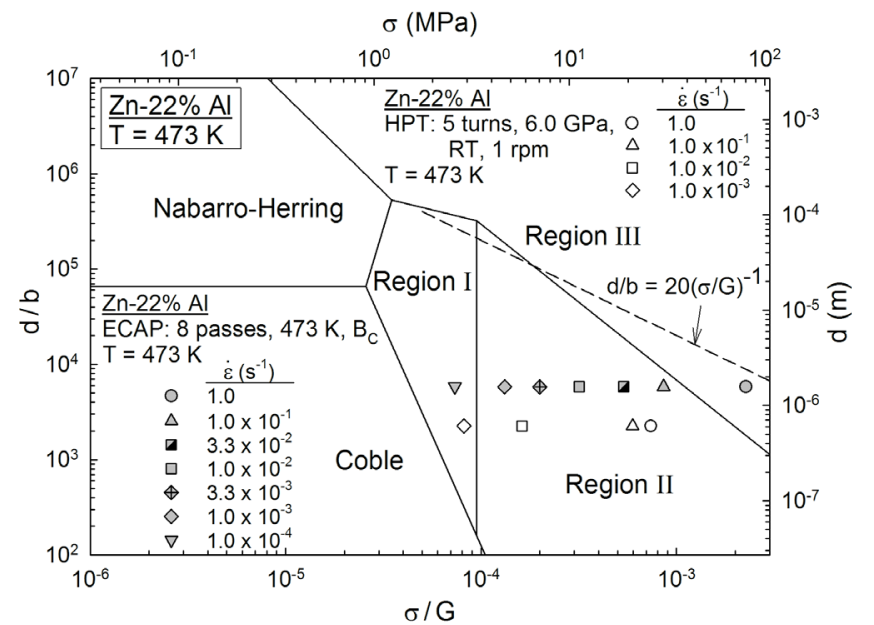

Fig. 7. A deformation mechanism map of normalized grain size versus normalized stress for the $\mathrm{Zn}-22 \% \mathrm{Al}$ alloy tested at $473 \mathrm{~K}$ [43]: experimental data of $\mathrm{Zn}-22 \% \mathrm{Al}$ alloys after ECAP [41] and HPT [43] are superimposed on the map.
$\mathrm{Zn}-22 \% \mathrm{Al}$ alloys without SPD processing [37] and the fields for Nabarro-Herring [45,46] and Coble [47] diffusion creep are based on the theoretical relationships for these two mechanisms. The dashed line in the map denotes the relationship which is defined experimentally that subgrains are formed under experimental testing conditions above the dashed line, thereby showing agreement with the field boundary between the superplastic region II and region III without superplasticity. The experimental data shown in Fig. 6 were superimposed on the map and all of the results for both the ECAP and the HPT $\mathrm{Zn}-22 \% \mathrm{Al}$ specimens provide an excellent agreement with the deformation mechanism map based on the theoretical relationship for the rate of flow. A recent paper summarizes the development of maps for superplastic UFG metals [48].

The superplastic forming industry is now well developed for manufacturing complex parts [49] but an advantage of introducing SPD processing is that it produces materials that can be formed extremely rapidly. An example is shown in Fig. 8 for the Al-3\% Mg-0.2\% Sc alloy where the disk labeled (a) was processed by ECAP and the other disks were pro- 


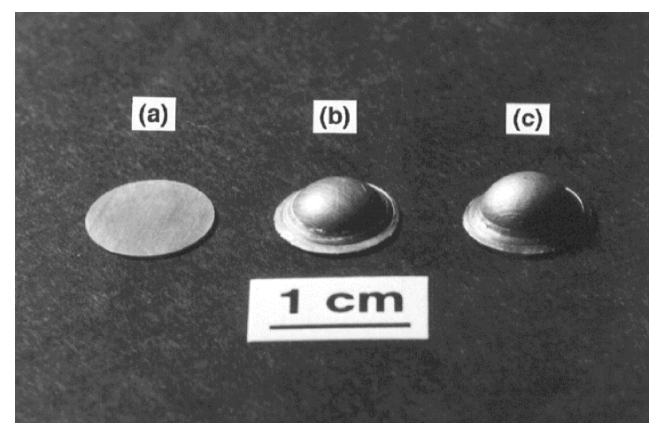

Fig. 8. Examples of superplastic forming at high strain rates in a gaspressure forming facility: the $\mathrm{Al}-\mathrm{Mg}-\mathrm{Sc}$ disk at (a) is untested after ECAP and the other disks were processed by ECAP and then held at $673 \mathrm{~K}$ and subjected to a gas pressure of 10 atmospheres for (b) 30 $\mathrm{s}$ and (c) $60 \mathrm{~s}$ [50].

cessed by ECAP and formed at $673 \mathrm{~K}$ under a pressure of 10 atmospheres for (b) 30 and (c) $60 \mathrm{~s}$ [50].

\section{Summary and conclusions}

1. Processing through the application of severe plastic deformation produces excellent grain refinement in both f.c.c. and h.c.p. metals but the mechanisms of grain refinement are different in these different crystal structures.

2. The exceptional grain refinement produced by SPD processing leads to excellent superplastic properties in many different materials. The optimum strain rate for superplasticity increases with a decrease in grain size.

3. Controlling the SPD processing parameters provides an opportunity for optimizing the superplastic properties. Examples are shown in magnesium alloys by introducing a preliminary extrusion step before ECAP processing and controlling the numbers of ECAP passes.

4. The occurrence of high strain rate superplasticity was observed in two-phase materials such as the $\mathrm{Zn}-22 \% \mathrm{Al}$ alloy processed by SPD. The flow mechanisms of UFG materials may be predicted by constructing a deformation mechanism map.

Acknowledgements. This work was supported in part by the NRF Korea funded by MoE under Grant No. NRF-2014057697 (MK), in part by Brazilian National Research Counsil (CNPq), FAPEMIG and CAPES (RBF), in part by the National Science Foundation of the United States under Grant No. DMR1160966 and in part by the European Research Council under ERC Grant Agreement No. 267464-SPDMETALS (TGL).

\section{References}

1. R.Z. Valiev, R.K. Islamgaliev, I.V. Alexandrov, Prog. Mater. Sci. 45, 103 (2000).

2. T.G. Langdon, Acta Mater. 61, 7035 (2013).

3. R.Z. Valiev, T.G. Langdon, Prog. Mater. Sci. 51, 881 (2006).

4. A.P. Zhilyaev, T.G. Langdon, Prog. Mater. Sci. 53, 893 (2008).
5. T.G. Langdon, Metall. Trans. A 13A, 689 (1982).

6. M. Kawasaki, T.G. Langdon, J. Mater. Sci. 42, 1782 (2007).

7. M. Kawasaki, T.G. Langdon, J. Mater. Sci. 49, 6487 (2014).

8. T.G. Langdon, Mater. Sci. Eng. A462, 3 (2007).

9. M. Furukawa, Y. Iwahashi, Z. Horita, M. Nemoto, T.G. Langdon, Mater. Sci. Eng. A257, 328 (1998).

10. D. Kuhlmann-Wilsdorf, Scr. Mater. 36, 173 (1997).

11. S.E. Ion, F.J. Humphreys, S.H. White, Acta Metall. Mater. 30, 1909 (1982).

12. A. Galiyev, R. Kaibyshev, G. Gottstein, Acta Mater. 49, 1199 (2001).

13. R.B. Figueiredo, T.G. Langdon, J. Mater. Sci. 44, 4758 (2009).

14. R.B. Figueiredo, T.G. Langdon, J. Mater. Sci. 45, 4827 (2010).

15. Z. Horita, K. Matsubara, K. Makii, T.G. Langdon, Scr. Mater. 47, 255 (2002).

16. K. Matsubara, Y. Miyahara, Z. Horita, T.G. Langdon, Acta Mater. 51, 3073 (2003).

17. H. Hasegawa, S. Komura, A, Utsunomiya, Z. Horita, M. Furukawa, M. Nemoto, T.G. Langdon, Mater. Sci. Eng. A265, 188 (1999).

18. S. Lee, A. Utsunomiya, H. Akamatsu, K. Neishi, M. Furukawa, Z. Horita, T.G. Langdon, Acta Mater. 50, 553 (2002).

19. F.A. Mohamed, T.G. Langdon, Phil. Mag. 32, 697 (1975).

20. T.G. Langdon, Acta Metall. Mater. 42, 2437 (1994).

21. Y. Ma, M. Furukawa, Z. Horita, M. Nemoto, R.Z. Valiev, T.G. Langdon, Mater. Trans. JIM 37, 336 (1996).

22. R.Z. Valiev, D.A. Salimonenko, N.K. Tsenev, P.B. Berbon, T.G. Langdon, Scr. Mater. 37, 1945 (1997).

23. K. Higashi, M. Mabuchi, T.G. Langdon, ISIJ Intl. 36, 1423 (1996).

24. M. Furui, H. Kitamura, H. Anada, T.G. Langdon, Acta Mater. 55, 1083 (2007).

25. Y. Iwahashi, J. Wang, Z. Horita, M. Nemoto, T.G. Langdon, Scr. Mater. 35, 143 (1996).

26. H. Watanabe, T. Mukai, K. Ishikawa, K. Higashi, Scr. Mater. 46, 851 (2002).

27. V.N. Chuvil'deev, T.G. Nieh, M.Yu. Gryaznov, A.N. Sysoev, V.I. Kopylov, Scr. Mater. 50, 861 (2004).

28. R. Lapovok, R. Cottam, P.F. Thomson, Y. Estrin, J. Mater. Res. 20, 1375 (2005).

29. R.B. Figueiredo, T.G. Langdon, Mater. Sci. Eng. A430, 151 (2006).

30. R. Lapovok, Y. Estrin, M.V. Popov, T.G. Langdon, Adv. Eng. Mater. 10, 429 (2008).

31. R.B. Figueiredo, T.G. Langdon, J. Mater. Sci. 43, 7366 (2008).

32. R.B. Figueiredo, T.G. Langdon, Mater. Sci. Eng. A503, 141 (2009).

33. R.B. Figueiredo, T.G. Langdon, Scr. Mater. 61, 84 (2009).

34. R.B. Figueiredo, T.G. Langdon, Mater. Sci. Eng. A501, 105 (2009).

35. R.B. Figueiredo, T.G. Langdon, Adv. Eng. Mater. 10, 37 (2008).

36. R.B. Figueiredo, T.G. Langdon, Mater. Sci. Forum 584586, 170 (2008).

37. H. Ishikawa, F.A. Mohamed, T.G. Langdon, Phil. Mag. 32, 1269 (1975). 
38. T.G. Langdon, F.A. Mohamed, Scr. Metall. 11, 575 (1977).

39. M.M.I. Ahmed, F.A. Mohamed, T.G. Langdon, J. Mater. Sci. 14, 2913 (1979).

40. D.W. Livesey, N. Ridley, J. Mater. Sci. 17, 2257 (1982).

41. M. Kawasaki, T.G. Langdon, Mater. Trans. 49, 84 (2008).

42. P. Kumar, C. Xu, T.G. Langdon, Mater. Sci. Eng. A429, 324 (2006).

43. M. Kawasaki, T.G. Langdon, Mater. Sci. Eng. A528, 6140 (2011).
44. T.G. Langdon, Mater. Sci. Eng. A137, 1 (1991).

45. F.R.N. Nabarro, Report of a Conference on Strength of Solids, The Physical Society, London, U.K. (1948). p. 75

46. C. Herring, J. Appl. Phys. 21, 437 (1950).

47. R.L. Coble, J. Appl. Phys. 34, 1679 (1963).

48. M. Kawasaki, T.G. Langdon, J. Mater. Sci. 47, 7726 (2012).

49. A.J. Barnes, J. Mater. Eng. Perform. 16, 440 (2007).

50. Z. Horita, M. Furukawa, M. Nemoto, A.J. Barnes, T.G. Langdon, Acta Mater. 48, 3633 (2000). 